\title{
Fetal exposure to nonsteroidal anti-inflammatory drugs and spontaneous abortions
}

\author{
Sharon Daniel MD MPH, Gideon Koren MD, Eitan Lunenfeld MD MHA, Natalya Bilenko MD PhD, \\ Ronit Ratzon BN MPH, Amalia Levy MPH PhD
}

\begin{abstract}
Background: Spontaneous abortion is the most common complication of pregnancy. Nonsteroidal anti-inflammatory drugs (NSAIDs) are widely used during pregnancy. Published data are inconsistent regarding the risk of spontaneous abortion following exposure to NSAIDs.
\end{abstract}

Methods: We performed a historical cohort study involving all women who conceived between January 2003 and December 2009 and who were admitted for delivery or spontaneous abortion at Soroka Medical Center, Clalit Health Services, Israel. A computerized database of medication dispensation was linked with 2 computerized databases containing information on births and spontaneous abortions. We constructed time-varying Cox regression models and adjusted for maternal age, diabetes mellitus, hypothyroidism, obesity, hypercoagulation or inflammatory conditions, recurrent miscarriage, in vitro fertilization of the current pregnancy, intrauterine contraceptive device, ethnic background, tobacco use and year of admission.
Results: The cohort included 65457 women who conceived during the study period; of these, $58949(90.1 \%)$ were admitted for a birth and 6508 (9.9\%) for spontaneous abortion. A total of 4495 (6.9\%) pregnant women were exposed to NSAIDs during the study period. Exposure to NSAIDs was not an independent risk factor for spontaneous abortion (nonselective cyclooxygenase [COX] inhibitors: adjusted hazard ratio [HR] 1.10, 95\% confidence interval [Cl] 0.99-1.22; selective COX-2 inhibitors: adjusted HR 1.43, 95\% Cl 0.792.59). There was no increased risk for specific NSAID drugs, except for a significantly increased risk with exposure to indomethacin (adjusted HR 2.8, 95\% Cl 1.70-4.69). We found no dose-response effect.

Interpretation: We found no increased risk of spontaneous abortion following exposure to NSAIDs. Further research is needed to assess the risk following exposure to selective COX-2 inhibitors.
Competing interests: None declared.

This article has been peer reviewed.

Correspondence to:

Amalia Levy,

lamalia@bgu.ac.il

CMAJ 2014. DOI:10.1503 /cmaj.130605
$\mathrm{T}$ he use of either prescription or over-thecounter nonsteroidal anti-inflammatory drugs (NSAIDs) is steadily increasing among pregnant women. ${ }^{1,2}$ Indicated mainly for their antipyretic, analgesic and anti-inflammatory effects, ${ }^{3}$ NSAIDs constitute a class of drugs that is widely used by pregnant women during the first trimester of pregnancy. ${ }^{2}$ Spontaneous abortion is the most common complication of pregnancy. Fifteen percent of clinically evident pregnancies end in miscarriage, ${ }^{4}$ with $80 \%$ of miscarriages occurring before the twelfth gestational week..$^{5-7}$ The incidence of subclinical pregnancy is even higher, ranging from $22 \%$ $26 \%$, as found in studies that assessed daily urinary human chorionic gonadotropin levels. ${ }^{6,7}$ Known and suspected risk factors for spontaneous abortion include parental genetic abnormalities, advanced maternal age, ${ }^{8}$ uterine malformations, ${ }^{9-11}$ endocrine diseases (e.g., diabetes mellitus, ${ }^{12}$ hypothyroidism, ${ }^{13}$ polycystic ovary syndrome $\left.{ }^{14}\right)$, hypercoagulability diseases, ${ }^{15,16}$ obesity, ${ }^{17}$ smoking ${ }^{18}$ and increased consumption of alcohol ${ }^{19}$ and caffeine. ${ }^{20}$ Previous studies assessing the risk of spontaneous abortion following exposure to NSAIDs have reported inconsistent results. ${ }^{21-24}$

Two case-control studies did not find increased use of acetylsalicylic acid or other NSAIDs among women who were admitted with spontaneous abortion compared with women who gave birth to a live infant. ${ }^{21,22}$ In contrast, 2 studies (cohort and nested case-control) have found exposure to NSAIDs to be a risk factor for spontaneous abortion. ${ }^{23,24}$ Because many women need NSAIDs and because half of all pregnancies are unplanned, ${ }^{25}$ the conflicting findings from past research have caused confusion and fear among pregnant women and their health care providers. We conducted a large historical cohort study to assess the risk of spontaneous abortion following maternal-fetal exposure to NSAIDs. 


\section{Methods}

We performed a historical cohort study involving all women aged 15-45 years registered with Clalit Health Services whose pregnancy was conceived between January 2003 and December 2009 and who were admitted for birth or who had a spontaneous abortion at Soroka Medical Center. About $70 \%$ of the women in the southern district of Israel are insured by Clalit Health Services. Soroka Medical Center is the tertiary hospital in the region; $98 \%$ of births in this region take place at this facility. ${ }^{26}$ No differences were found between the population insured by the Clalit health maintenance organization and the population insured by other health organizations in the southern district of Israel. ${ }^{27}$

To create the study cohort, we linked 3 computerized databases: the deliveries database of the obstetrics and gynecology division (demographic data, diagnoses before and during pregnancy, self-reported tobacco use during pregnancy, gestational age at delivery, pregnancy results for all births that occurred at Soroka Medical Center); the Soroka Medical Center hospitalization database (hospital admissions data including demographic information, main and background medical diagnoses [International Classification of Diseases, ninth revision (ICD-9) codes], letters of admission and discharge to and from the hospital, and operating room report); and the Clalit Health Services medication database (medications dispensed during the pregnancy). The medication database includes the Anatomic Therapeutic Chemical classification codes of the drugs, their commercial and generic names, the dates on which each drug was dispensed, dosage, and dose dispensed in terms of defined daily dose. We assembled the databases using personal identification numbers (unique numbers assigned to all citizens by the Israeli Ministry of the Interior and used throughout life).

The study was approved by the local institutional ethics committee at Soroka Medical Center in accordance with the principles of the Declaration of Helsinki.

\section{Study design and definition of variables}

We defined 2 main exposure groups according to the category of NSAIDs used: non-selective cyclooxygenase (COX) inhibitors (ibuprofen, diclofenac, naproxen, etodolac, indomethacin, lornoxicam or nabumetone) or COX-2 selective inhibitors (celecoxib, etoricoxib or rofecoxib). The first day of the participant's last menstrual period was retrieved from the medical letter of admission and discharge, from operating room reports for spontaneous abortions, and from the obstetrics and gynecology department database for births. A woman was categorized as exposed if an NSAID had been dispensed between the first day of the last menstrual period and the day before the date of admission to hospital for a pregnancy that resulted in a spontaneous abortion or 20 weeks' gestation for pregnancies that ended with birth. Thus, the exposure period began 2 weeks before conception.

The day of the first dispensation of a drug was defined as the first day of exposure. Exposure was also characterized by the number of defined daily doses dispensed during the followup period. The defined daily doses for prescription NSAIDs are as follows: ibuprofen $1200 \mathrm{mg}$, diclofenac $100 \mathrm{mg}$, naproxen $500 \mathrm{mg}$, etodolac $400 \mathrm{mg}$, lornoxicam $12 \mathrm{mg}$, nabumetone $1000 \mathrm{mg}$, etoricoxib $400 \mathrm{mg}$, indomethacin $100 \mathrm{mg}$, celecoxib $200 \mathrm{mg}$ and rofecoxib $25 \mathrm{mg}$. The sum of defined daily doses dispensed was stratified into 3 categories $(1-2,3-9,10)$.

Medical diagnoses were defined based on the following ICD-9 codes: spontaneous abortion $(634,632,631)$, hypothyroidism (244), obesity $(278,649.1)$, diabetes mellitus $(250,357.2)$, hypercoagulation diseases $(286.4,289.81$, $286.53)$, inflammatory diseases $(710,714,720)$, recurrent spontaneous abortions $(646.33,629.81)$, tobacco use $(305.1,649)$ and presence of an intrauterine contraceptive device (V4551, Z975).

\section{Statistical analysis}

We used SPSS (version 18) for statistical analyses. We compared the characteristics of the pregnant women using $\chi^{2}$ or Fisher exact tests for categorical variables and Student $t$ test for continuous variables. To control for immortal time bias, ${ }^{28}$ we used time-varying multivariate Cox regression models to determine whether exposure to NSAIDs is an independent risk factor for spontaneous abortion. Immortal time bias may occur in cohort studies in which drug exposure is defined dichotomously (exposed v. unexposed). Women who survive longer in follow up have a higher chance of being assigned to the exposed group; this creates a bias in which NSAIDs would be found to be protective against spontaneous abortion.

We adjusted all models for diagnosis of diabetes mellitus, hypothyroidism, obesity, hypercoagulation and inflammatory disorders and recurrent miscarriages, in vitro fertilization (IVF) for conception of the current pregnancy, selfreported tobacco use during pregnancy, the presence of an intrauterine contraceptive device, maternal age, ethnic group (i.e., Jewish v. Bedouin Muslim) and year of admission. We used a categorical time-varying multivariate Cox 
regression model to assess whether greater exposure (in terms of defined daily dose) was associated with greater risk of spontaneous abortion. Hazard ratios (HRs) and 95\% confidence interval (CIs) were calculated.

\section{Results}

A total of 66547 women who conceived between January 2003 and December 2009 were admitted to Soroka Medical Center: 58949 $(88.5 \%)$ for delivery and $7598(11.4 \%)$ because of spontaneous abortion. Of the women with spontaneous abortion, data about gestational age at admission were missing for 1090 (14.3\%) women; these cases were not included in the analysis. In total, 4495 of the 65457 (6.9\%) included pregnant women were exposed to NSAIDs during the study period, of which 4424 $(98.4 \%)$ were exposed to nonselective COX inhibitors and $71(1.6 \%)$ to $\mathrm{COX}-2$ selective inhibitors. In total, $4.2 \%$ were exposed to ibuprofen (2732 women), $1.4 \%$ to diclofenac (919), $1.0 \%$ to naproxen $(671), 0.41 \%$ to etodolac (272), $0.2 \%$ to indomethacin (132), $0.046 \%$ to rofecoxib (30), $0.043 \%$ to celecoxib (28), $0.035 \%$ to etoricoxib (23), $0.004 \%$ to nabumetone (3) and $0.003 \%$ to lornoxicam (2). Some women were exposed to more than 1 medication of the NSAID class: 259 women were exposed to 2 medications, 26 were exposed to 3 medications and 2 were exposed to 4 medications.

A comparison of maternal characteristics between the 2 NSAID exposure groups and unexposed women is presented in Table 1 . Women exposed to NSAIDs during pregnancy were older and had significantly higher proportions of tobacco use, hypothyroidism and inflammatory diseases compared with unexposed women. In addition, the exposed group contained a higher proportion of women who had undergone in vitro fertilization compared with the unexposed group.

The unadjusted and adjusted hazard ratios for spontaneous abortion following exposure to NSAIDs are presented in Table 2. In the unexposed group, 10\% (6132/60 962) experienced a spontaneous abortion. In the nonselective NSAIDs exposure group, 8.2\% (364/4424) of exposed women experienced a spontaneous

Table 1: Maternal and pregnancy-related characteristics

\begin{tabular}{|c|c|c|c|}
\hline \multirow[b]{3}{*}{ Characteristic } & \multicolumn{3}{|c|}{ No. $(\%)^{*}$} \\
\hline & \multicolumn{2}{|c|}{ NSAID exposure $\dagger$} & \multirow[b]{2}{*}{$\begin{array}{c}\text { No NSAID exposure } \\
n=60962\end{array}$} \\
\hline & $\begin{array}{c}\text { Nonselective COX } \\
\text { inhibitors } \\
n=4424\end{array}$ & $\begin{array}{c}\text { COX-2 selective } \\
\text { inhibitors } \\
n=71\end{array}$ & \\
\hline Hypercoagulation disease & $\begin{array}{l}1(0.02) \\
p=0.8\end{array}$ & $\begin{array}{c}0(0) \\
p=0.9\end{array}$ & $17(0.02)$ \\
\hline In vitro fertilization & $\begin{array}{l}100(2.3) \\
p<0.001\end{array}$ & $\begin{array}{c}0(0) \\
p=0.3\end{array}$ & $847(1.4)$ \\
\hline $\begin{array}{l}\text { Presence of an intrauterine } \\
\text { device }\end{array}$ & $\begin{array}{l}16(0.4) \\
p=0.2\end{array}$ & $\begin{array}{c}0(0) \\
p=0.7\end{array}$ & $159(0.3)$ \\
\hline Tobacco use & $\begin{array}{l}78(1.8) \\
p=0.04\end{array}$ & $\begin{array}{c}0(0) \\
p=0.3\end{array}$ & $850(1.4)$ \\
\hline Inflammatory disease & $\begin{array}{c}8(0.2) \\
p=0.06\end{array}$ & $\begin{array}{c}2(2.8) \\
p<0.001\end{array}$ & $56(0.1)$ \\
\hline Hypothyroidism & $\begin{array}{l}88(2.0) \\
p=0.02\end{array}$ & $\begin{array}{l}1(1.4) \\
p=0.9\end{array}$ & $943(1.5)$ \\
\hline Obesity & $\begin{array}{l}24(0.5) \\
p=0.6\end{array}$ & $\begin{array}{c}0(0) \\
p>0.9\end{array}$ & $287(0.47)$ \\
\hline Mother's age, yr, mean \pm SD & $\begin{array}{l}30.2 \pm 5.8 \\
p<0.001\end{array}$ & $\begin{array}{l}33.1 \pm 5.8 \\
p<0.001\end{array}$ & $28.9 \pm 5.8$ \\
\hline \multicolumn{4}{|l|}{ Ethnic group $\ddagger$} \\
\hline Bedouin & $2802(63.3)$ & $43(60.6)$ & 38904 (63.8) \\
\hline Jewish & $\begin{array}{c}1622(36.7) \\
p=0.5\end{array}$ & $\begin{array}{c}28(39.4) \\
p=0.6\end{array}$ & $22058(36.2)$ \\
\hline
\end{tabular}


Table 2: Risk of spontaneous abortion following exposure to nonsteroidal anti-inflammatory drugs: time-varying multivariate Cox regression models

\begin{tabular}{|c|c|c|c|c|c|}
\hline \multirow[b]{2}{*}{ Exposure } & \multirow{2}{*}{$\begin{array}{c}\text { No. of } \\
\text { participants }\end{array}$} & \multirow{2}{*}{$\begin{array}{l}\text { No. of } \\
\text { abortions }\end{array}$} & \multirow{2}{*}{$\begin{array}{l}\text { Median gestational } \\
\text { age at exposure, } d\end{array}$} & \multicolumn{2}{|c|}{ Spontaneous abortion hazard ratio $(95 \% \mathrm{Cl})$} \\
\hline & & & & Unadjusted & Adjusted* \\
\hline Not exposed & 60962 & 6132 & & & \\
\hline Nonselective COX inhibitors & 4424 & 373 & 31 & $1.13(1.01-1.25)$ & $1.10(0.99-1.22)$ \\
\hline Naproxen & 671 & 53 & 27 & $1.87(0.66-1.17)$ & $0.97(0.74-1.28)$ \\
\hline Etodolac & 272 & 4 & 20.5 & $1.26(0.88-1.80)$ & $1.28(0.91-1.79)$ \\
\hline Indomethacin & 132 & 15 & 89 & $3.54(2.20-5.71)$ & $2.82(1.70-4.69)$ \\
\hline COX-2 selective inhibitors & 71 & 11 & 25 & $1.97(1.12-3.47)$ & $1.43(0.79-2.59)$ \\
\hline
\end{tabular}

Table 3: Risk of spontaneous abortion following exposure to nonsteroidal anti-inflammatory drugs, by defined daily dose: categorical time-varying multivariate Cox regression model

\begin{tabular}{|c|c|c|}
\hline $\begin{array}{l}\text { No. of defined daily } \\
\text { doses* }\end{array}$ & $\begin{array}{c}\text { Spontaneous abortions } \\
\% \text { (no./total no.) }\end{array}$ & $\begin{array}{c}\text { Adjusted hazard ratio } † \\
(95 \% \mathrm{Cl})\end{array}$ \\
\hline 0 & $10.0(6$ 251/62 432) & 1.00 (reference) \\
\hline $1-2$ & $5.6(55 / 977)$ & $0.93(0.77-1.13)$ \\
\hline $3-9$ & $10.5(101 / 961)$ & $0.76(0.54-1.07)$ \\
\hline$\geq 10$ & $9.2(99 / 1080)$ & $1.23(0.94-1.62)$ \\
\hline \multicolumn{3}{|c|}{$\begin{array}{l}\text { Note: } \mathrm{Cl}=\text { confidence interval. } \\
\text { *Assumed average maintenance dose per day for a drug when it is used in adults for its main } \\
\text { indication. } \\
\text { †Adjusted for maternal age, hypothyroidism, obesity, diabetes mellitus, hypercoagulation } \\
\text { state, uterine disorders, presence of an intrauterine contraceptive device, history of recurrent } \\
\text { abortions, in vitro fertilization used to conceive the current pregnancy, inflammatory diseases } \\
\text { and ethnic group (Bedouin v. Jewish). }\end{array}$} \\
\hline
\end{tabular}

abortion (crude HR 1.13, 95\% CI 1.01-1.25; adjusted HR 1.10, 95\% CI 0.99-1.22), with a median gestational age at first exposure of 31 days. Among those exposed to COX-2 selective inhibitors, $16.9 \%(12 / 71)$ experienced a spontaneous abortion (crude HR 1.97, 95\% CI 1.123.47; adjusted HR 1.43, 95\% CI 0.79-2.59), with a median gestational age at first exposure of 23 days.

With the exception indomethacin, we found no increased risk of spontaneous abortion following exposure to a specific NSAID (Table 2). We found a significant association between first trimester exposure to indomethacin and spontaneous abortion (adjusted HR 2.82, 95\% CI 1.704.69). Among women exposed to indomethacin, $12.9 \%$ (17/132) experienced spontaneous abortion, compared with $10 \%(6132 / 60962)$ in the unexposed group; the median exposure day was 89. The complete models for the assessment of the risk of spontaneous abortion following exposure to nonselective $\mathrm{COX}$ inhibitors or selective COX-2 inhibitors are presented in Appendix 1 and Appendix 2 (available at www.cmaj.ca /lookup/suppl/doi:10.1503/cmaj.130605/-/DC1)

We found no dose-response effect between exposure to NSAIDs and spontaneous abortion in our univariate analysis or after adjustment using a categorical time-varying Cox regression model (Table 3).

\section{Interpretation}

We found no important associations between exposure to NSAIDs, either by group or for most specific NSAID drugs, and risk of spontaneous abortion. However, we found an increased risk of spontaneous abortion following exposure to indomethacin. We believe that this result is possibly due to reverse causation bias. Indomethacin is a well-known tocolytic drug indicated to treat preterm labour. ${ }^{29}$ Half of the exposures to indomethacin occurred after the median day of pregnancies that ended in spontaneous abortion. Moreover, the median exposure day for indomethacin was significantly higher than the median exposure day for other NSAIDs. Therefore, we assume that indomethacin was dispensed toward the end of pregnancy for an indication - likely preterm labour — different than for other NSAIDs. We found no association after omitting exposures that occurred during the 4 days before spontaneous abortion.

We found an unadjusted increased risk of spontaneous abortion following exposure to COX-2 selective inhibitors; this risk became nonsignificant after multivariate analysis. Because the exposure group included only 71 
pregnancies, we believe that further research is needed to address this question. We also found a modestly increased unadjusted risk of spontaneous abortion following exposure to nonselective COX inhibitors.

Our databases contain data about alcohol dependence and abuse. A large proportion of the southern district population comprises religious Jewish or Bedouin Muslim communities. Because women of child-bearing age in these groups rarely or never use alcohol, none of the women who were admitted for birth or miscarriage had a diagnosis of alcohol dependence or abuse.

In this study, gestational age at the time of admission for spontaneous abortions was defined accurately. Therefore, exposures were defined accurately throughout the period of pregnancy both for births and spontaneous abortions, thereby preventing misclassification bias. Defining gestational age at the time of first exposure allowed us to perform time-varying analyses, overcoming the problem of immortal time bias. ${ }^{28}$ Furthermore, our databases are based on drug dispensation, rather than prescription, making adherence more likely.

We adjusted the results for nearly all known risk factors for spontaneous abortion. As such, we have reduced the impact of residual confounding manifested in previous studies. Our results are supported by a dose-response analysis conducted for the defined daily doses of the drugs.

\section{Comparison with other studies}

Our findings are consistent with those from a matched case-control study that assessed the risk of spontaneous abortion following first trimester exposure to acetylsalicylic acid and those of a case-control study that assessed the risk following exposure to NSAIDs. ${ }^{21,22}$ However, 2 other studies (cohort and nested case-control) reported an increased risk of spontaneous abortion following exposure to NSAIDs. ${ }^{23,24}$

In a cohort study conducted in the United States, ${ }^{23}$ exposure to NSAIDs was found to be associated with spontaneous abortion (HR 1.8, 95\% CI 1.0-3.2). Information on exposure was obtained by interviews performed at entry to the study at a mean gestational age of 6 weeks, with only 1055 women out of 2729 agreeing to participate, possibly introducing both recall and selection bias. ${ }^{30}$ A recently published nested casecontrol study reported an increased risk of spontaneous abortion following exposure to NSAIDs. ${ }^{24}$ However, exposure was defined by prescription, rather than dispensation, of NSAIDs during pregnancy, which necessarily limited the ability of the researchers to assess usage of over-the-counter NSAIDs. ${ }^{31}$ In that study, only 36\% of pregnant women in Quebec were included, ${ }^{32}$ all of whom were insured by the public health insurance program because of low socioeconomic class. Our study included $70 \%$ of the women in the southern district of Israel. ${ }^{26}$

The 2 previous studies that found an association between NSAIDs use and spontaneous abortion did not adjust for important known risk factors for spontaneous abortion, including hypercoagulable state, uterine disorders, the presence of an intrauterine device and IVF, which have been found to be associated with spontaneous abortions and may expose the results to residual confounding.

\section{Limitations}

We retrieved information regarding drug dispensation from the Clalit Health Services dispensation database; data on adherence to therapy, therefore, were not available. However, previous studies have found information in pharmacy databases to be compatible with medication use in general..$^{33-36}$

A limitation of the study may be the availability of ibuprofen as an over-the-counter drug. However, interview data indicate that less than $2 \%$ of NSAID use is unrecorded (Appendix 3, available at www.cmaj.ca/lookup/suppl/doi:10 .1503/cmaj.130605/-/DC1).

Data regarding gestational age at admission were missing for 1090 (14.3\%) women whose pregnancy ended in spontaneous abortion. We found no significant differences in maternal characteristics or risk factors for spontaneous abortion between women with or without data on gestational age. Furthermore, we re-analyzed the data while assigning mean gestational day at spontaneous abortion for this group of pregnancies and found similar results. These results minimize the likelihood of selection bias.

Some of the clinically apparent spontaneous abortions do not come to medical attention and, therefore, these cases were technically unaccounted for in our cohort. The possibility of misclassification bias arises by assuming that women with nonapparent spontaneous abortion may have been exposed to NSAIDs at higher proportions. However, it is not likely that women who do not seek care for a spontaneous abortion have a higher proportion of medication use, making the likelihood of differential misclassification bias low.

\section{Conclusion}

We did not find an increased risk of spontaneous abortion following exposure to NSAIDs, either as groups or individual drugs, with the exception of a significant association found for indomethacin. Further research is needed to assess the risk following exposure to selective COX-2 inhibitors. 


\section{References}

1. Daniel S, Matok I, Gorodischer R, et al. Major malformations following exposure to nonsteroidal antiinflammatory drugs during the first trimester of pregnancy. J Rheumatol 2012;39:2163-9.

2. Werler MM, Mitchell AA, Hernandez-Diaz S, et al. Use of overthe-counter medications during pregnancy. Am J Obstet Gynecol 2005; 193:771-7.

3. Grosser T, Smyth E, FitzGerald G. Anti-inflammatory, antipyretic,and analgesic agents; pharmacotherapy of gout. In Brunton L, Chabner B, Knollmann B, editors. Goodman \& Gilman's the pharmacological basis of therapeutics. 12th ed. New York (NY): McGraw-Hill; 2011.

4. Prernoll M, Benson R. Early pregnancy risks. In: Alan HD, Lauren $\mathrm{N}$, editors. Current diagnosis \& treatment, obstetrics \& gynecology. 10th ed. New York (NY): McGraw-Hill; 2007.

5. Harlap S, Shiono PH. Alcohol, smoking, and incidence of spontaneous abortions in the first and second trimester. Lancet 1980; 2:173-6.

6. Wang X, Chen C, Wang L, et al. Conception, early pregnancy loss, and time to clinical pregnancy: a population-based prospective study. Fertil Steril 2003;79:577-84.

7. Wilcox AJ, Weinberg CR, O'Connor JF, et al. Incidence of early loss of pregnancy. N Engl J Med 1988;319:189-94.

8. Nybo Andersen AM, Wohlfahrt J, Christens P, et al. Maternal age and fetal loss: population based register linkage study. BMJ 2000;320:1708-12.

9. Pritts EA, Parker WH, Olive DL. Fibroids and infertility: an updated systematic review of the evidence. Fertil Steril 2009;91: 1215-23.

10. Klatsky PC, Tran ND, Caughey AB, et al. Fibroids and reproductive outcomes: a systematic literature review from conception to delivery. Am J Obstet Gynecol 2008;198:357-66.

11. Salim R, Regan L, Woelfer B, et al. A comparative study of the morphology of congenital uterine anomalies in women with and without a history of recurrent first trimester miscarriage. Hum Reprod 2003;18:162-6.

12. Mills JL, Simpson JL, Driscoll SG, et al. Incidence of spontaneous abortion among normal women and insulin-dependent diabetic women whose pregnancies were identified within 21 days of conception. N Engl J Med 1988;319:1617-23.

13. Abalovich M, Gutierrez S, Alcaraz G, et al. Overt and subclinical hypothyroidism complicating pregnancy. Thyroid 2002;12:63-8.

14. Clifford K, Rai R, Watson H, et al. Does suppressing luteinising hormone secretion reduce the miscarriage rate? Results of a randomised controlled trial. BMJ 1996;312:1508-11.

15. Robertson L, Wu O, Langhorne P, et al. Thrombophilia in pregnancy: a systematic review. Br J Haematol 2006;132:171-96.

16. Branch DW, Khamashta MA. Antiphospholipid syndrome: obstetric diagnosis, management, and controversies. Obstet Gynecol 2003; 101:1333-44.

17. ESHRE Capri Workshop Group. Nutrition and reproduction in women. Hum Reprod Update 2006;12:193-207.

18. Mishra GD, Dobson AJ, Schofield MJ. Cigarette smoking, menstrual symptoms and miscarriage among young women. Aust $N Z J$ Public Health 2000;24:413-20.

19. Henriksen TB, Hjollund NH, Jensen TK, et al. Alcohol consumption at the time of conception and spontaneous abortion. Am J Epidemiol 2004;160:661-7.

20. Weng X, Odouli R, Li DK. Maternal caffeine consumption during pregnancy and the risk of miscarriage: a prospective cohort study. Am J Obstet Gynecol 2008;198:279.e1-8.

21. Keim SA, Klebanoff MA. Aspirin use and miscarriage risk. Epidemiology 2006; 17:435-9.

22. Nielsen GL, Skriver MV, Pedersen L, et al. Danish group reanalyses miscarriage in NSAID users. BMJ 2004;328:109.

23. Li DK, Liu L, Odouli R. Exposure to non-steroidal anti-inflammatory drugs during pregnancy and risk of miscarriage: population based cohort study. BMJ 2003;327:368.
24. Nakhai-Pour HR, Broy P, Sheehy O, et al. Use of nonaspirin nonsteroidal anti-inflammatory drugs during pregnancy and the risk of spontaneous abortion. CMAJ 2011;183:1713-20.

25. Finer LB, Zolna MR. Unintended pregnancy in the United States: incidence and disparities, 2006. Contraception 2011 2011:84:478-85.

26. Angel D. Patterns of fertility in 2006 [article in Hebrew]. Central Bureau of Statistics: Jerusalem (Israel); 2007. Available: www.cbs.gov.il/hodaot2007n/01_07_215b.pdf (accessed 2014 Jan. 15).

27. Rafaela C. National Insurance Institute of Israel, periodic survey [article in Hebrew]. National Insurance Institute of Israel: Jerusalem (Israel); 2012. Available: www.btl.gov.il/Publications /survey/Documents/seker_238.pdf (accessed 2013 Sept. 1).

28. Suissa S. Immortal time bias in pharmaco-epidemiology. Am J Epidemiol 2008;167:492-9.

29. Roman APM. Late pregnancy complications. In: Alan HD, Lauren $\mathrm{N}$, editors. Current diagnosis \& treatment, obstetrics \& gynecology. 10th ed. New York (NY): McGraw-Hill; 2007.

30. Schiavetti B, Clavenna A, Campi R, et al. NSAIDs during pregnancy and risk of miscarriage: true risks or only suspicions? BMJ 2004;328:108, author reply 108-9.

31. Clark CA, Spitzer KA, Laskin CA, et al. Spontaneous abortion and NSAIDs. CMAJ 2011;183:2145, author reply 2145-6.

32. Bérard A, Lacasse A. Validity of perinatal pharmacoepidemiologic studies using data from the RAMQ administrative database. Can J Clin Pharmacol 2009;16:e360-9.

33. Lanas A, Polo-Tomas M, Roncales P, et al. Prescription of and adherence to non-steroidal anti-inflammatory drugs and gastroprotective agents in at-risk gastrointestinal patients. Am J Gastroenterol 2012;107:707-14.

34. Ray WA, Griffin MR. Use of Medicaid data for pharmacoepidemiology. Am J Epidemiol 1989;129:837-49.

35. West SL, Savitz DA, Koch G, et al. Recall accuracy for prescription medications: self-report compared with database information. Am J Epidemiol 1995;142:1103-12.

36. Johnson RE, Vollmer WM. Comparing sources of drug data about the elderly. J Am Geriatr Soc 1991;39:1079-84.

Affiliations: Departments of Public Health (Daniel, Bilenko, Ratzon, Levy), Pediatrics (Daniel) and Obstetrics and Gynecology (Lunenfeld), Faculty of Health Sciences, Ben-Gurion University of the Negev, Soroka Medical Center, Beer-Sheva, Israel; Regional Health Office, Southern District (Bilenko), Israeli Ministry of Health, Israel; Motherisk (Koren), Division of Clinical Pharmacology and Toxicology, Hospital for Sick Children, University of Toronto, Toronto, Ont.; BenGurion Motherisk Obstetric Registry of Exposure Collaboration (BeMORE Collaboration) (Daniel, Koren, Levy), BenGurion University, Beer-Sheva, Israel.

Contributors: Sharon Daniel, Amalia Levy and Gideon Koren designed the research and wrote the manuscript. Sharon Daniel and Amalia Levy performed the research and analyzed the data. Eitan Lunenfeld contributed to the clinical interpretation and writing of the manuscript. Natalya Bilenko and Ronit Ratzon were responsible for performing the interviews. All of the authors approved the final version submitted for publication.

Funding: This research was not funded by any company or organization.

Acknowledgements: The authors thank the staff in the computer unit of Clalit Southern District and Soroka Medical Center and Einat Hasid and Rotem Tsabari. 